\title{
Methoprene, a juvenile hormone analogue, modifies maturation and emergence in overwintering Osmia rufa $\mathrm{L}$. adults
}

\author{
Karol GIEJDASz ${ }^{1}$, Monika FliszKIEWICZ ${ }^{1}$, and Oskar WASIELEWSKI ${ }^{1}$ (]) \\ ${ }^{1}$ Department of Zoology, Poznań University of Life Sciences, Wojska Polskiego 71C, 60-625 Poznań, Poland
}

Received 27 May 2021 - Revised 21 October 2021 - Accepted 15 November 2021

\begin{abstract}
The development of methods aimed at activation of imagos at any point of wintering provides a compelling potential avenue to utilize bees for pollination of greenhouse crops during autumn, winter, and early spring. In this study, we tested methoprene, a juvenile hormone $(\mathrm{JH})$ analogue as a chemical stimulant to end a diapause of Osmia rufa L. and enable bee activation and emergence under experimental conditions. The application of methoprene significantly reduced the emergence time of adult bees in winter months as compared to vehicle (acetone) and negative controls. Bees treated with methoprene started to emerge 3-6 days earlier than bees from acetone and control groups and finished emergence 2-6 days earlier too. Statistically significant differences were observed between methoprene and controls groups of male and female in all tested incubation periods. It was also observed that the effects of methoprene were significantly more effective in female specimens during the first 2 months of winter. Moreover, in females, methoprene improved reproductive traits such as an increase in the size of terminal oocytes. Similarly, in males, methoprene treatment resulted in a significant increase in a seminal vesicle size and dynamic elevation of spermatozoa number. Taken together, our results indicate that methoprene may play an important role in the termination of diapause, bee activation, and emergence.
\end{abstract}

juvenile hormone / methoprene / Osmia rufa / overwintering / reproduction

\section{INTRODUCTION}

Insect pollination is fundamental for most agricultural crops as well as for the health of the ecosystem. In modern agriculture, the production of fruits, vegetables, and virtually all cereals depends upon insect pollination (Klein et al. 2007). The area cultivated with pollinatordependent crops has increased exponentially over the last several decades, suggesting that the need for insect pollinators will also greatly increase in the future (Aizen et al. 2009). The

Corresponding author: O. Wasielewski,

oskar.wasielewski@up.poznan.pl

Manuscript editor: Zachary Huang worldwide insect-pollinated crops have traditionally depended on a single species, the honey bee (Apis mellifera). However, during the past decade, the number of honey bee colonies has sharply declined, due to human pressure (Gallai et al. 2009). As a result, it has been suggested to develop alternative pollinator species suitable for crops in the diverse geographical locations (Klein et al. 2007). The diversification of pollination assemblages for crop is clearly important (Rader et al. 2012). Examples of introduction of non-Apis species for agricultural pollination include the use of bumble bees, primarily for the pollination of greenhouse tomatoes, the solitary bees Osmia sp. for the pollination of orchard crops, Megachile and Nomia for alfalfa 
pollination, and social stingless bees to pollinate coffee crops (Bosch and Kemp 2001).

The red mason bee, Osmia rufa L., is a native European solitary bee that has recently been adopted as an alternative pollinator of fruit, especially apples, pears, plums, raspberries, and strawberries (Giejdasz and Wilkaniec 2002). This univoltine species completes its development from egg to the imago stage across the spring and summer period (Wilkaniec and Giejdasz 2003). Moreover, O. rufa, like most species of Osmia genus, exhibits an obligatory diapause during its life cycle. Namely, adults emerge in September and overwinter as the imago stage inside a cocoon through the winter months (Giejdasz and Wilkaniec 2002). In natural conditions, like the other species of this genus, the bees enclose during the spring as the temperature increases (Bosch and Kemp 2000). This is one of the canonical examples of a reproductive diapause that involves an arrest of reproductive development with a resting state marked with reduced metabolic activity. The process has been well characterized in beetles, butterflies, grasshoppers, and diverse species of flies (Tatar and Yin 2001).

In many insects, the duration of diapause is controlled by a multitude of factors (Denlinger, 2002; Koštál, 2006). Beyond the environmental inducing factors such as photoperiod and temperature, the phenomenon of diapause is regulated by complex neuroendocrine processes (Denlinger 2002; Macrae 2005). The endocrine regulation is particularly important especially in the reproductive diapause where juvenile hormone (JH) appears to play a crucial role (Simonet et al. 2004). A decrease in JH production in the corpus allatum (CA) induces cessation of reproduction, specifically, the arrest of vitellogenesis and regression of the ovaries (Gilbert et al. 2000; Adams et al. 2002; De Loof 2008).

Exposure to higher temperature at the end of diapause and post-diapause has been reported to induce emergence of bees (Sgolastra et al. 2011). Due to the fact that this process proceeds slowly, it is difficult to synchronize flights and blooming for practical applications in agriculture. A standardized chemical stimulant that could accelerate the end of diapause in a synchronized manner would be very beneficial for any practical applications.

In line with the above, we evaluated the $\mathrm{JH}$ analogue methoprene in the current study as a factor that stimulates the end of diapause, bee activation, and emergence. We demonstrate that when applied during diapause, methoprene significantly accelerated the emergence of females during the first 2 months of winter. Moreover, in females, methoprene improved reproductive traits such as an increase in the size of terminal oocytes. Similarly, in males, methoprene treatment resulted in a significant increase in a seminal vesicle size and dynamic elevation of spermatozoa number. Furthermore, as reported by us earlier, it mobilizes fat body proteins and other reserve substances (Wasielewski et al. 2011).

This work provides evidence that the development of a method aimed at adult bee activation at any point of wintering can potentially allow their effective utilization for pollination of greenhouse crops from autumn to early spring. Carefully controlled acceleration of adults' emergence can also reduce the costs associated with incubation of bees in an artificial environment.

\section{MATERIAL AND METHODS}

\subsection{Biological material}

Experiments were conducted during the wintering period of Osmia rufa. The experimental material consisted of bees reared in artificial nests made of reed stalks following the method of Wójtowski and Wilkaniec (1978) and originated from nests kept in natural conditions in Przybroda orchards, Swadzim experimental station, and the botanical garden near the Department of Zoology (Poznań, Poland). The O. rufa overwinters as an imago inside its cocoon. The entire period of diapause spans a period from November to end of January and includes initiation, maintenance, and termination phases. During these months, the ambient environmental temperatures and humidity were monitored (an average temperature, November $2.78^{\circ} \mathrm{C}$, 
humidity $90 \%$; December $1.66{ }^{\circ} \mathrm{C}$, humidity $90 \%$; January $-2.77{ }^{\circ} \mathrm{C}$, humidity $86 \%$ ). From the 16th of October, the settled nests were kept in a cooled incubator (Panasonic MIR-254-PE) at $4{ }^{\circ} \mathrm{C} \pm 0.5$ and humidity $50 \%$. The experiments started at the beginning of December and were completed in March before the natural emergence period. Once a month, bees were taken out of cooler, nest tubes were dismantled, and cocoons were removed from nest cells. Cocoons were sexed according to their size and position within the nest. Three groups (treated, vehicle control, negative control) of bee cocoons were selected for each activation term. The experimental cocooned bees (1100 males and 1170 females) were treated topically on the cocoon surface once a day, for 5 consecutive days with a $200 \mu \mathrm{g}$ of methoprene dissolved in $5 \mu \mathrm{l}$ acetone (Sigma, Poland) (Robinson et al. 1992; O’Donnel and Jeanne 1993; Malka et al. 2009). The vehicle control was treated with $5 \mu \mathrm{l}$ of acetone alone, and the negative control was not treated. During application time, the cocoons of all groups were kept separately on plates with specially prepared holes and placed in an environmental chamber (model MLR-350H Sanyo) at a temperature $20{ }^{\circ} \mathrm{C} \pm 0.5{ }^{\circ} \mathrm{C}$ and relative humidity $60 \% \pm 1 \%$. After the application, the temperature in the chamber was turned up to $24{ }^{\circ} \mathrm{C} \pm 0.5^{\circ} \mathrm{C}$, and under these conditions, the bees were kept until emergence (Figure 1).

The number of emerged $O$. rufa adults was scored each day until all live bees had emerged from the cocoons (the mortality in males was $15.1 \%$, and in females, it was $11 \%$ ). The sex of emerged adults was determined according to morphological traits. The bees were settled into acrylic glass cuboid cages $(25 \mathrm{~cm} \times 25 \mathrm{~cm} \times 40 \mathrm{~cm})$ and treated as one experimental group. One cage comprised of 50 bees of both sexes ( 25 females and 25 males). The emerged adult bees were kept in the laboratory at $20{ }^{\circ} \mathrm{C} \pm 1{ }^{\circ} \mathrm{C}$ and $12: 12 \mathrm{~h}$ photoperiod. They were fed ad libitum with a sucrose solution $(1: 1 \mathrm{v} / \mathrm{v})$ served in a Petri dish $(5 \mathrm{~cm}$ diameter) with floating circle of perforated comb foundation to prevent from drowning. The cages were inspected every 2 days, and the number of dead bees were scored. The sucrose solution was replaced every time the dead insects were removed. This procedure was repeated until the last dead bee was scored.

\subsection{Body mass, fat body, and ovarian index}

To evaluate the effect of methoprene during overwintering, nest pipes were dismantled, and cocoons were sexed. To estimate the mass depletion of the bees during the activation, the male and female cocoons were weighed twice, at the beginning of incubation time and on a day of first adult emergence. The mass of bees that emerged before the second mass measurement was omitted from analyses. Empty cocoons were not

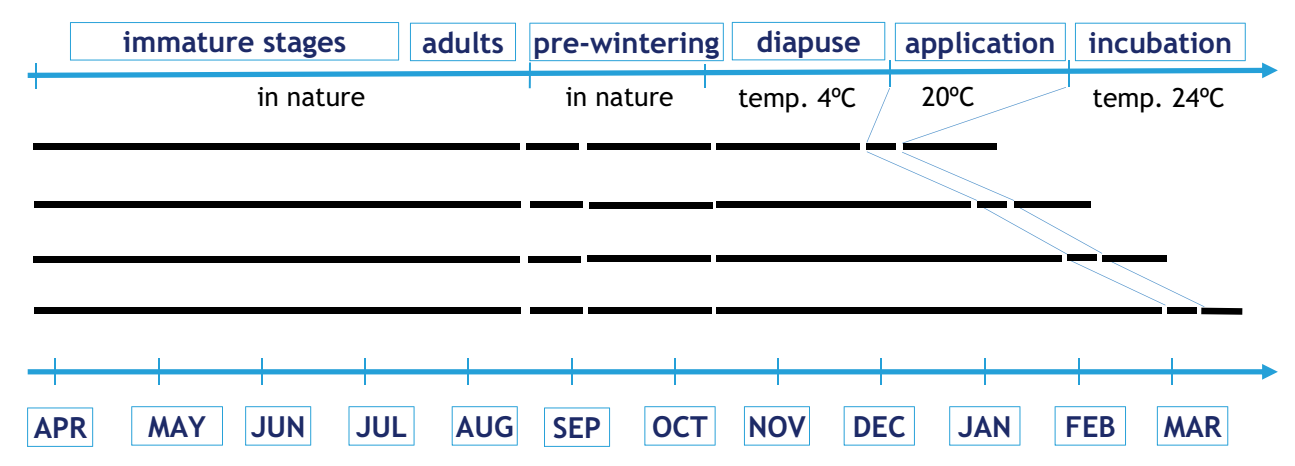

Figure 1. Developmental stages and adult life of Osmia rufa L. with the time of methoprene application and incubation. 
weighed, because the adult bees tore a substantial part of the cocoons using their mandibles. Therefore, it was not possible to determine the initial adult bee mass as the difference between the mass of cocoon with adult and mass of empty cocoon.

Initially after cutting the abdominal tergite, the fat body structure was visually evaluated under stereoscopic microscope according to the developmental index (a scale from 1 to 5 with 5 being the best developed structure) proposed by Maurizio (1954).

To estimate the effect of methoprene on oocyte growth in $O$. rufa females, oocyte sizes were measured. Decapitated females were submerged in physiological saline $(130 \mathrm{mM} \mathrm{NaCl}$, $1.3 \mathrm{mM} \mathrm{KCl}, 0.9 \mathrm{mM} \mathrm{CaCl}{ }_{2} \bullet 2 \mathrm{H}_{2} \mathrm{O}, 1.9 \mathrm{mM}$ $\mathrm{MgCl}_{2} \bullet 6 \mathrm{H}_{2} \mathrm{O}, 2 \mathrm{mM} \mathrm{NaHCO}$ ), and the ovaries were dissected under a Stereo Lumar V.12 (Carl Zeiss, Germany) stereoscopic microscope. The length and width of terminal oocytes were determined using the AxioVision software (Carl Zeiss, Germany). The size of terminal oocytes was measured for each ovariole in the ovary, and ovarian index was calculated as the value derived from multiplying the length and width of terminal oocyte for each ovariole, following which they were divided by the total number of ovarioles. To determine the number of oocytes in ovarioles, only oocytes with a width of at least $0.1 \mathrm{~mm}$ were considered.

\subsection{Seminal vesicle and spermathecae analysis}

Spermathecae and vesicles were dissected under stereomicroscope. Every single spermatheca and seminal vesicle were placed in a drop of $0.9 \% \mathrm{NaCl}$ solution on a watch glass. Seminal vesicles were measured with size calculated as the value derived from multiplying the length and width. Reproductive organs were analyzed before mating (seminal vesicle in males) and 10 days after mating (spermathecae in females). To perform sperm count, the tissues were gently torn with microforceps (World Precision Instruments, USA), and their contents were thoroughly mixed with the saline solution to a volume of $50 \mu \mathrm{l}$ and subsequently diluted with distilled water to $200 \mu \mathrm{l}$ of final solution. Distilled water kills sperm cells facilitating their counting. A drop of the solution was placed on the Fuchs-Rosenthal hemocytometer and examined with the use of a phase contrast microscope (Nikon; $20 \times 10$ magnitude). Sperm count from 5 large squares of the hemocytometer $(2 \mu \mathrm{l} \mathrm{solu-}$ tion) was converted to a total sperm number in the spermatheca or seminal vesicle (Woyke and Jasiński 1973).

\subsection{Statistical analysis}

All statistical analyses and graphs were generated with Statistica software package (Statsoft, v. 12). A two-way ANOVA was conducted with post hoc Tukey test to separate out means within and between treatment groups. The Kruskal-Wallis test was used for multiple comparison of emergence times in the groups (control, acetone, methoprene). The analysis was conducted at the significance level $\alpha=0.05$, separately for males and females. In the figures, parameters are presented as means \pm standard deviation (SD).

\section{RESULTS}

\subsection{Time and rate of bee emergence}

Bees after methoprene treatment emerged faster than control groups (acetone and untreated) in winter months (December, January, February, March) (Figure 2a, b). The most significant differences between the methoprene groups and control groups were observed in December. Median emergence times of the females in December were 33 days after treatment with methoprene, 38 days for females treated with acetone, and 36 days for untreated females (K-W test, $H=13.552$; df, 2, 113; $p<0.01)$ and 27, 33, and 34 days for males, respectively (K-W test, $H=30.745$; df, 2, 107; $p<0.001)$. In January and February, similarly to December, the bees treated 
A

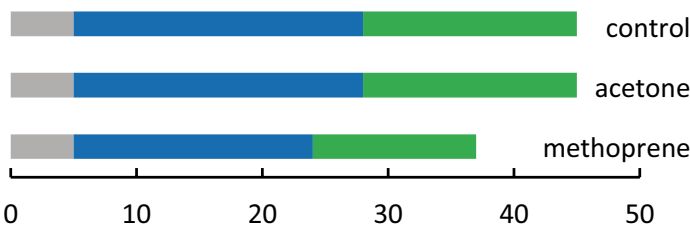

A

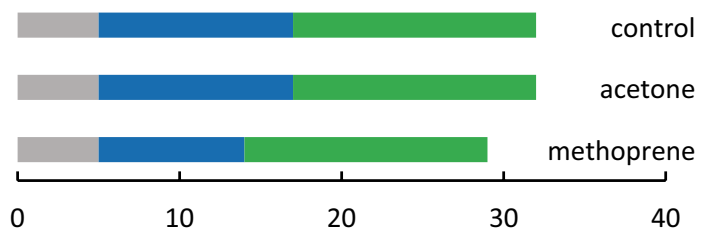

A

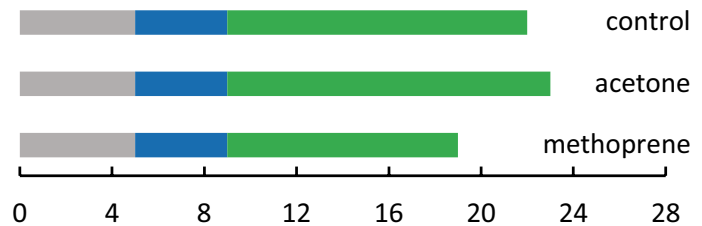

A

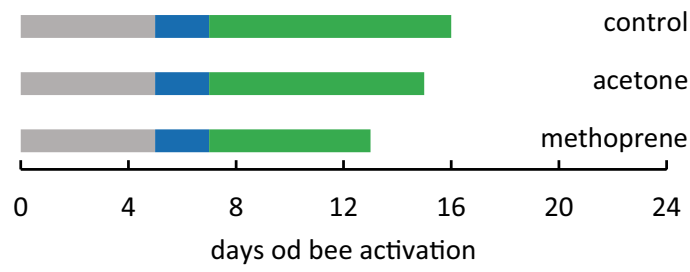

application incubation =emergence

Feb

Mar
Dec

B

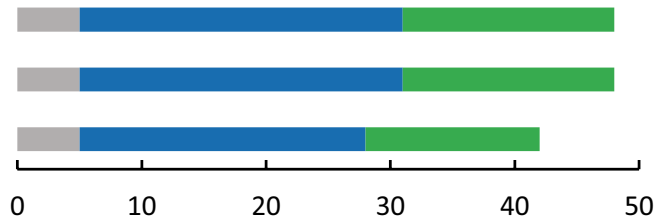

Jan
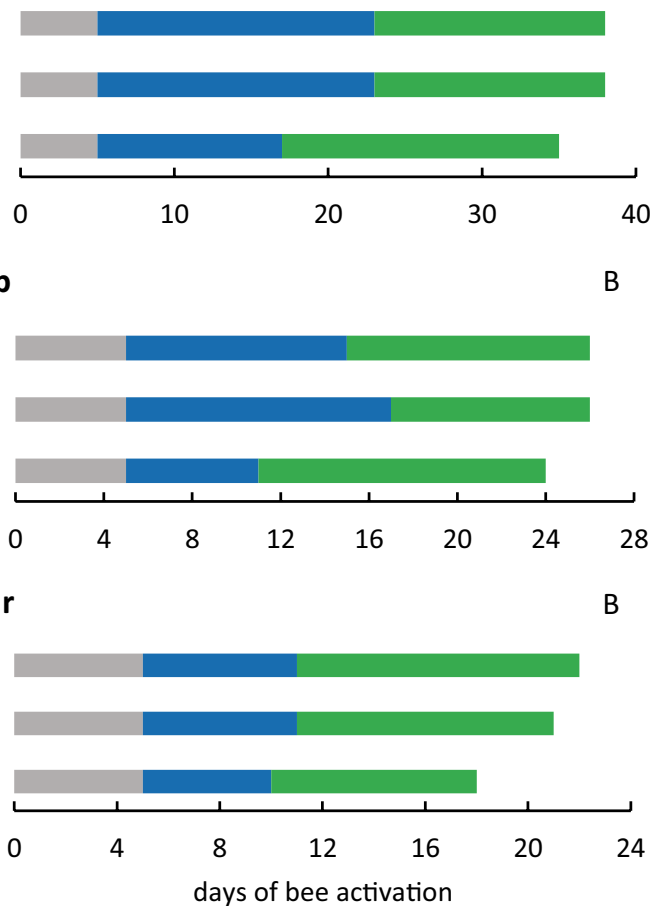

application $\square$ incubation emergence

Figure 2. Effect of methoprene treatment on the time and rate of emergence of $O$. rufa males (a) and females (b) activated in different terms in wintering period (December to March).

with methoprene emerged faster than those treated with acetone and untreated (January, K-W test; female, $H=63.284$; df, 2, 298; $p<0.001$; male, $H=51.295$; df, 2, 246; $p<0.001$; February, K-W test; female, $H=43.512$; df, 2, 249; $p<0.001$; male, $H=12.029$; df, 2, 184; $p<0.002$ ) (Figures 2 and 3). In the last of winter month, March, we also noted statistically significant difference in the emergence time of adult bees among groups from various treatments. Most of the females in methoprene experimental group (K-W, $H=43.893$; df, 2,$250 ; p<0.001)$ as well as males (K-W test, $H=19.274$; df, 2, 249; $p<0.001)$ emerged earlier compared to control. In general, the first bees from methoprene treated females and males emerged 1-3 days earlier than acetone and control. We also observed that the effect of methoprene is more pronounced in the first 2 months of winter (Figure 2a, b). Moreover, in females, the effect of methoprene persisted longer (compared to the control), probably due to the female biology of solitary bees (Figure $2 b$ ). 


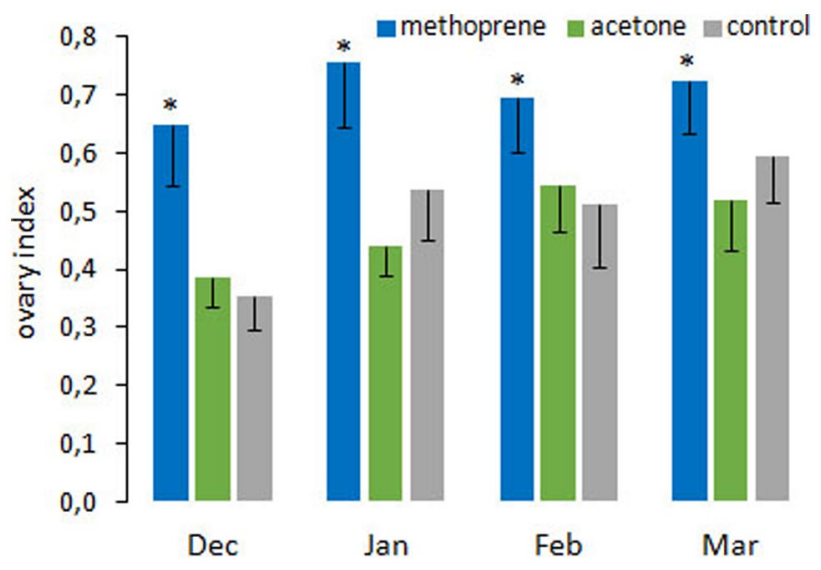

Figure 3. Effect of methoprene $(200 \mu \mathrm{g})$ treatment on the size of terminal oocytes isolated from $O$. rufa females. Mean values \pm SD were based on measurement of oocytes from a total 196 females for each treatment. Significant differences $(* p<0.05)$ from the control (untreated and acetone treated) females are indicated by asterisk (post hoc Tukey test).

\subsection{Reproductive traits of females}

Methoprene treatment resulted in a significant increase in the size of terminal oocytes (Figure 3). Differences were observed between methoprene and controls groups of females in particular incubation periods (December to March). The impact and significance of methoprene on terminal oocyte size increase were dictated by the month in which the experimental groups were treated. During winter months, a dynamic growth of ovaries was observed. In particular, after methoprene application, oocytes increased in size in a statistically significant manner. All ovary index calculations indicated significant differences between methoprene applicated females and controls in all winter months (ANOVA $F_{2,196}=7.906 p<0.001$ ). Methoprene application was the most effective in December (oocyte size, methoprene (M) $0.64 \pm 0.44 \mathrm{~mm}$; acetone (A) $0.38 \pm 0.20 \mathrm{~mm}$; control (C) $0.35 \pm 0.24 \mathrm{~mm}$ ).

During first 2 months of wintering time (December to January), the oocytes from methoprene treated females increased in number (December, 7.33 \pm 0.57 ; January, $8.06 \pm 2.08$ ) compared to control groups (December, $6.83 \pm 2.06$ (A), $6.5 \pm 1.15$ (C); January, $6.78 \pm 1.0(\mathrm{~A}), 7.56 \pm 2.51$ (C) (treatment,
$\left.F_{2,59}=0.866 p>0.05\right)$. In the next 2 months, February to March, differences in number of oocytes between all groups were not found to be statistically significant in the tested population of females (month, $F_{3,59}=1.118 ; p>0.05$ ).

In successive months, gradual changes in the number of spermatozoa in spermathecae were noticed as indicated by two-way ANOVA $\left(F_{3,108}=16.391 ; p<0.001\right)$. We observed progressive increase in spermatozoa number $\left(\right.$ December $=23 \times 10^{3}$, January $=28 \times 10^{3}$, March $=36 \times 10^{3}$ ) with statistically significant differences between experimental groups $\left(F_{2,108}=34.146 ; p<0.001\right.$; post hoc Tukey test $)$.

\subsection{Seminal vesicle size and sperm number}

The experiments demonstrated that the methoprene increased the seminal vesicle size during months of wintering (ANOVA $F_{3,107}=10.143 p<0.001$ ) (Figure 4). Tukey post hoc tests indicated a statistically significant differences between methoprene injected males and controls in the first two winter months (December to January) (ANOVA $F_{2,107}=7.577 ; p<0.001$ ) (Figure 4). In the next months (February to March), measurements 


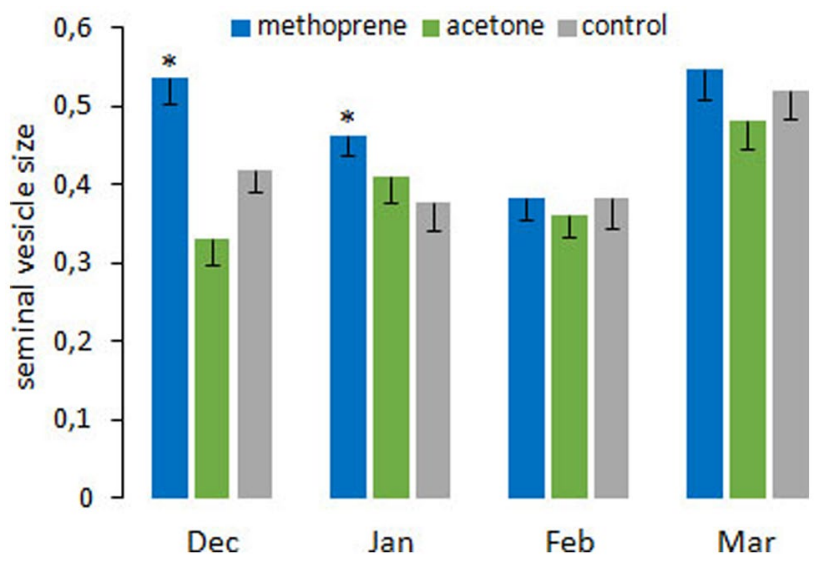

Figure 4. Effect of methoprene $(200 \mu \mathrm{g})$ treatment on the size of seminal vesicle from $O$. rufa males. Mean values \pm SD were based on measurement of SV from a total 107 males for each treatment. Significant differences $\left({ }^{*} p<0.05\right)$ from the control (untreated and acetone treated) males are indicated by asterisk (post hoc Tukey test).

did not reveal any apparent differences in size (Tukey post hoc test; $p>0.05$ ). Similarly to females, methoprene application was the most effective in December (seminal vesicle size, M $0.53 \pm 0.09 \mathrm{~mm}$; A $0.33 \pm 0.10 \mathrm{~mm}, \mathrm{C}$ $0.41 \pm 0.08 \mathrm{~mm})$.

During wintering time (December to March), a dynamic elevation of spermatozoa number in seminal vesicle was observed between experimental groups and controls (ANOVA $F_{2,108}=97,890 ; p<0.001$ ). The data indicate that the number of spermatozoa raised during all tested months, from $2.07 \times 10^{5}$ in December till $2.95 \times 10^{5}$ in March (ANOVA $\left.F_{3,108}=16.391 ; p<0.001\right)$.

\subsection{Body mass and fat body index}

At the beginning of experimental period (December), the body mass of females was $148.2 \pm 4.70 \mathrm{mg}$ and $85.6 \pm 6.66 \mathrm{mg}$ for males. In all tested groups, methoprene treated and controls after second measurement (January), body mass decreases insignificantly: $10 \%(\mathrm{M}), 10 \%$ (A), and 7\% (C) for females and 8\% (M), 9\% (A), and $9 \%(\mathrm{C})$ for males. In successive months (January to March), gradual changes in body mass both sexes were noticed (males $F_{3,890}=17.85$, $p<0.001$; females $F_{3,806}=13.71, p<0.001$ ) (Tables I and II). Moreover, interaction between treatment and month was detected (males

Table I. Mass of female cocoons (mg) weighted at the beginning of incubation time $(*)$ and in a day of first adult emergence $(* *)$.

\begin{tabular}{|c|c|c|c|c|c|c|}
\hline \multirow{2}{*}{$\begin{array}{l}\text { Treatment } \\
\text { Time }\end{array}$} & \multicolumn{2}{|c|}{ Methoprene } & \multicolumn{2}{|c|}{ Acetone } & \multicolumn{2}{|c|}{ Control } \\
\hline & * & $* *$ & * & $* *$ & $*$ & $* *$ \\
\hline 10 Dec/03 Jan & 148.2 & 132.3 & 143.4 & 127.7 & 149.2 & 131.7 \\
\hline 13/24 Jan & 135.7 & 121.3 & 145.0 & 132.5 & 138.9 & 127.6 \\
\hline 10/24 Feb & 143.2 & 133.9 & 152.2 & 143.1 & 150.8 & 142.8 \\
\hline 03/14 Mar & 144.8 & 132.7 & 131.8 & 121.7 & 117.2 & 107.8 \\
\hline
\end{tabular}


Table II. Mass of male cocoons (mg) weighted at the beginning of incubation time $\left(^{*}\right)$ and in a day of first adult emergence $(* *)$.

\begin{tabular}{llllllll}
\hline Treatment & \multicolumn{2}{l}{ Methoprene } & & \multicolumn{2}{l}{ Acetone } & & \multicolumn{2}{l}{ Control } \\
\cline { 2 - 3 } Time & $*$ & & & $*$ & $*$ & $*$ \\
\hline 10 Dec/03 Jan & 85.6 & 78.3 & & 85.5 & 78.0 & 84.8 & 77.4 \\
13/24 Jan & 84.5 & 76.6 & 79.3 & 72.7 & 86.6 & 81.1 \\
10/24 Feb & 76.4 & 72.3 & 74.5 & 70.8 & 70.0 & 66.4 \\
03/14 Mar & 83.5 & 80.8 & 87.8 & 83.1 & 76.9 & 74.9 \\
\hline
\end{tabular}

$F_{6,890}=2.21, p<0.05$; females $F_{6,806}=5.27$, $p<0.001)$.

The body mass is strongly correlated with content of fat body. During the winter months, the fat body development stage remained at the same level (months, males $F_{3,107}=4.144$, $p>0.05$; females $F_{3,108}=2.616, p>0.05$ ) in methoprene treated and controls and ranged between 3 and 3.2 for both females and males (treatment, males $F_{2,107}=1.373, p>0.05$; females $F_{2,108}=0.854, p>0.05$ ) (Table III).

\section{DISCUSSION}

In this study, it was found that the application of juvenile hormone analogue reduced the emergence time of adult $O$. rufa bees during winter months. Experimentally treated bees emerged faster than control (median emergence time: females, 33 days (38 days for acetone treatment; 36 days in control); males, 27 days (33 days in acetone treatment; 34 days in control)). Methoprene treatment induced positive changes in traits related to reproduction (increase in terminal oocytes and seminal vesicle size and in sperm amount). We also observed that in females, the effect of methoprene is more prominent in the first 2 months of winter and persists longer.

Insect diapause is a dynamic process and consists of several successive phases (Koštál 2006). In $O$. rufa, the precise staging of different phases of diapause has not been defined. $O$. rufa overwinters as an imago inside its cocoon in November, and diapause terminates towards the end of January, after a rise in environmental temperature. The entire period of diapause spans a period from November to the end of January and includes initiation, maintenance, and termination phases. This process varies between other

Table III. Changes in the fat body developmental index observed in Osmia rufa males and females during 4 months of wintering period (according to Maurizio scale). Mean values were based on measurement from 107 males and 108 females. Index was calculated as a mean of all observation.

\begin{tabular}{|c|c|c|c|c|c|c|}
\hline & \multicolumn{2}{|c|}{ Methoprene } & \multicolumn{2}{|c|}{ Acetone } & \multicolumn{2}{|c|}{ Control } \\
\hline & Male & $\overline{\text { Female }}$ & Male & $\overline{\text { Female }}$ & Male & Female \\
\hline Dec & 2.8 & 2.9 & 2.7 & 2.7 & 2.6 & 3.1 \\
\hline Jan & 3.2 & 3.5 & 3.0 & 3.3 & 2.9 & 3.2 \\
\hline Feb & 3.1 & 3.3 & 3.1 & 3.3 & 2.9 & 2.6 \\
\hline Mar & 3.4 & 3.1 & 3.1 & 3.1 & 3.2 & 2.9 \\
\hline
\end{tabular}


species belonging to a genus Osmia sp. Both $O$. rufa (Linnaeus) and O. cornuta (Latreille) (Hymenoptera: Megachilidae) overwinter in cocoons as diapausing adults. However, there are differences in the termination of their diapause (Krunić and Stanisavljević 2006). Under natural conditions. O. rufa appears in spring about 2 weeks later than $O$. cornuta. On the other hand, in $O$. lignaria, diapause commences a few days after eclosion, and after a short period of maintenance, diapause termination occurs within approximately 100 days after adult emergence (Sgolastra et al. 2010). In O. rufa, even though the actual period of diapause is completed, during the next 2 months, the adults remain in the cocoons. This time corresponds to a postdiapause quiescence, during which low metabolic rates are maintained exogenously, while temperatures are still too low for morphogenesis (or emergence) and is shorter than in O. lignaria (Sgolastra et al. 2010).

According to ecophysiological phases of diapause defined by Koštál (2006), a model of diapause was adopted for $O$. lignaria phenology by Sgolastra et al. (2010) wherein the intensity entering into diapause increases during the first 30 days of pre-wintering time and is maintained for the subsequent period of up to 30 days. During this period, it is impossible to activate adults with using higher temperature. It is possible to do so during the next step of diapause (from 60 till 100 days of overwintering) when the intensity of diapause decreases gently. Our results indicate that the $\mathrm{JH}$ analogue, methoprene, may play an important role in the termination of diapause. It is well illustrated by the acetone control and untreated females. In these females, exposure to control conditions during 5 days of experiments did not result in significant differences in adult emergence. In experimental groups, methoprene administration in December induced emergence after 40 days of application, and all males and $92.9 \%$ of females emerged. At the same time, controls demonstrated just over $70 \%$ and $50 \%$ emergence of males and females, respectively. In consecutive months (e.g., February $>120$ days of overwintering; March $>150$ days of overwintering) in both sexes, the application of methoprene accelerated an emergence but in more effective way in females. Furthermore, also in females, methoprene treatment resulted in a significant increase in the size of terminal oocytes between experimental and controls groups of female in all incubation terms (December to March). Similarly, topical application of methoprene to diapausing insects such as flies, beetles, or moths has also been reported to induce reproductive development even in unfavorable conditions (Kim and Krafsur 1995; Zdarek et al. 2000; Yamamura et al. 2008). Moreover, the $\mathrm{JH}$ analogue, methoprene, was used to assess its influence on seminal vesicle size and sperm count. In the treated group of $O$. rufa males, we noted significant changes in the size of seminal vesicle and spermatozoa number compared with non-treated or acetone-treated males. Many earlier studies show that JH stimulates maturation of reproductive organs in males and females of diverse insects (Wigglesworth 1936; Loher 1961; Blaine and Dixon 1973; Herman 1975; Piulachs et al. 1992; Bloch et al. 2000; Heming 2003; Shpigler et al. 2020). In contrast, some reports demonstrated contradictory effects of methoprene on physiological maturation in honeybee males (Harano 2013). The most information about the spermatogenesis in bees comes from honeybee drones. We postulate that it is unlikely that JH functions as an inhibitor of sexual maturation in drones because the $\mathrm{JH}$ production and its hemolymph titer increase with maturation of reproductive organs (Giray and Robinson 1996; Harano et al. 2008). In honeybee males, spermatozoa produced in the testes during the pupal period are transferred to seminal vesicle in the early adult period (Lago et al. 2020). But to this time, there has been no experimental evidence to affirm a potential role of juvenile hormone in spermatogenesis in genus other than Apis. It is worth noting that the metoprene may not affect the sperm count (spermatogenesis). However, in our opinion, it may contribute to the differentiation and the conversion of spermatids into sperm (spermiogenesis).

In insects that diapause as adults, nutrient reserves accumulated in fat body prior to diapause are critical for restoring post-diapause 
functions, including the rebuilding of tissues atrophied as part of the diapause program and for providing energy for post-diapause activities, such as dispersal and reproduction (Hahn and Denlinger 2007; 2011; Treanore and Amsalem 2020). Therefore, increased body weight loss and fat body depletion may compromise postdiapause performance. Early developing individuals suffer greater weight loss and fat body depletion and usually have short post-winter lifespan and poor overall vitality (Bosch et al. 2010). Our observations indicate that the body mass was slightly reduced, but the reduction was not statistically significant. In all tested groups, methoprene treated and controls medians of body mass were similar for both females and males. The body mass is strongly correlated with the content of fat body. During experiments, the fat body development stage remains at the same level. Of particular importance is the lack of reduction in weight for the groups treated with methoprene. It is important that the positive gonadotropic effect of methoprene doesn't decrease at the same time the body condition and vitality. Furthermore, the overall healthy condition of the bees is further indicated by the presence of sperm in female spermathecae. We observed progressive increase in spermatozoa number in particular months of wintering.

We believe that the development of hormonal methods for the control of diapause (reduce or eliminate diapause) may be successfully used in the future to obtain adult pollinator insects beyond the period of their natural life cycle. Control of diapause will open the possibility for additional generations of pollinators and enable the use of alternative bee species as managed pollinators in greenhouses and field plots outside their natural flight period. Finally, our results may also be used to devise new methods to control diapause in Osmia rufa, which will enable the activation of adult bees at various times during their lifecycle.

\section{ACKNOWLEDGEMENTS}

The authors would like to thank Prof. Natraj Krishnan, Mississippi State University, USA, and Prof. Donald Wlodkowic, RMIT University, Melbourne, Australia, for their constructive criticism and linguistic corrections of this manuscript.

\section{AUTHOR CONTRIBUTION}

Karol Giejdasz, Monika Fliszkiewicz, and Oskar Wasielewski conceived this research and designed experiments; Karol Giejdasz, Monika Fliszkiewicz, and Oskar Wasielewski performed experiments; Karol Giejdasz and Oskar Wasielewski analyzed data and conducted statistical analyses; Oskar Wasielewski wrote the manuscript; Karol Giejdasz, Monika Fliszkiewicz, and Oskar Wasielewski participated in the revisions of it. All authors read and approved the final manuscript.

\section{FUNDING}

This project was supported by the National Centre for Research and Development (PBS2/A8/17/2013).

\section{AVAILABILITY OF DATA AND MATERIAL}

Not applicable.

\section{CODE AVAILABILITY}

Not applicable.

\section{DECLARATIONS}

Ethics approval Not applicable.

Consent to participate Not applicable.

Consent for publication Not applicable.

Conflict of interest The authors declare no competing interests.

Open Access This article is licensed under a Creative Commons Attribution 4.0 International License, which permits use, sharing, adaptation, distribution and reproduction in any medium or format, as long as you give appropriate credit to the original author(s) and the source, provide a link to the Creative Commons licence, and indicate if changes were made. The images or other third party material in this article are included in the article's Creative Commons licence, unless indicated otherwise in a credit line to the material. If material is not included in the article's Creative Commons licence and your intended use is not permitted by statutory regulation or exceeds the permitted use, you will need to obtain permission directly from the copyright holder. To view a copy of this licence, visit http://creativecommons.org/licenses/by/4.0/. 


\section{REFERENCES}

Adams, T.S., Filipi, P.A., Yi, S.X. (2002) Effect of age, diapause and juvenile hormone on oogenesis and the amount of vitellogenin and vitellin in the twospotted stink bug, Perillus bioculatus (Heteroptera: Pentatomidae). J. Insect. Physiol. 48, 477-486

Aizen, M.A., Garibaldi, L.A., Cunningham, S.A., Kleian, A.M. (2009) How much does agriculture depend on pollinators? Lessons from longterm trends in crop production. Ann. Bot. 103, 1579-1588

Blaine, W.D., Dixon, S.E. (1973) The effect of juvenile hormone on the function of the accessory gland of the adult male cockroach Periplaneta americana (Orthoptera: Blattidae). Can. Entomol. 105, 1275-1280

Bloch, G., Borst, D.W., Huang, Z.Y., Robinson, G. E., Cnaani, J., Hefetz, A. (2000) Juvenile hormone titers, juvenile hormone biosynthesis, ovarian development and social environment in Bombus terrestris. J. Insect. Physiol. 46, 47-57

Bosch, J., Kemp,W.P. (2000) Development and emergence of the orchard pollinator Osmia lignaria (Hymenoptera: Megachilidae). Environ. Entomol. 29, 8-13

Bosch, J., Kemp,W.P. (2001) How to manage the blue orchard bee As an orchard pollinator. USDA Agricultural Research Service

Bosch, J.F., Sgolastra, F., Kemp, W.P. (2010) Timing of eclosion affects diapause development, fat body consumption and longevity in Osmia lignaria, a univoltine, adult-wintering solitary bee. J. Insect. Physiol. 56, 1949-1957

De Loof, A. (2008) Ecdysteroids, juvenile hormone and insect neuropeptides: recent successes and remaining major challenges. Gen. Comp. Endocrinol. 155, 3-13.

Denlinger, D.L. (2002) Regulation of diapauses. Annu. Rev. Entomol. 47, 93-122

Gallai, N., Salles, J.-M., Settele, J., Vaissière, B.E. (2009) Economic valuation of the vulnerability of world agriculture confronted with pollinator decline. Ecol. Econ. 68, 810-821

Giejdasz, K., Wilkaniec, Z. (2002) Individual development of the red mason bee (Osmia rufa L., Megachilidae) under natural and laboratory conditions. J. Apic. Sci. 46, 51-57

Gilbert, L.I., Granger, N.A., Roe, M.R. (2000) The juvenile hormones: historical facts and speculations on future research directions. Insect. Biochem. Mol. Biol 30, 617-622

Giray, T., Robinson, G.E. (1996) Common endocrine and genetic mechanisms of behavioral development in male and worker honey bees and the evolution of division of labor. Proc. Natl. Acad. Sci. U. S. A. 93, 11718-11722
Hahn, D.A., Denlinger, D.L. (2007) Meeting the energetic demands of insect diapause: nutrient storage and utilization. J. Insect. Physiol. 53, 760-773

Hahn, D.A., Denlinger, D.L. (2011) Energetics of insect diapause. Annu. Rev. Entomol. 56, 103-121

Harano, K., Sasaki, K., Nagao, T., Sasaki, M. (2008) Influence of age and juvenile hormone on brain dopamine level in male honeybee (Apis mellifera): association with reproductive maturation. J. Insect. Physiol. 54, 848-853

Harano, K. (2013) Effects of juvenile hormone analog on physiological and behavioral maturation in honeybee drones. Apidologie. 44, 586-599

Heming, B.S. (2003) Insect development and evolution. Cornell University Press

Herman, W.S. (1975) Juvenile hormone stimulation of tubular and accessory glands in male Monarch butterflies. Comp. Biochem. Physiol. A. 51, 507-510

Kim, Y., Krafsur, E.S. (1995) In vivo and in vitro effects of 20-hydroxyecdysone and methoprene on diapause maintenance and reproductive development in Musca autumnalis. Physiol. Entomol. 20, 52-58

Klein, A.-M., Vaissière, B.E., Cane, J.H., SteffanDewenter, I., Cunningham, S.A., Kremen, C., Tscharntke, T. (2007) Importance of pollinators in changing landscapes for world crops. Proc. R. Soc. Lon. B. Biol. Sci. 274, 303-313

Koštál, V. 2006 Eco-physiological phases of insect diapause. J. Insect. Physiol. 52, 113-127

Krunić, M.D., Stanisavljević, L.Ž. (2006) Supercooling points and diapause termination in overwintering adults of orchard bees Osmia cornuta and $O$ rufa (Hymenoptera: Megachilidae). Bull. Entomol. Res. 96, 323-326

Lago, D.C., Martins, J.R., Dallacqua, R.P., Santos, D.E., Bitondi, M.M.G, Hartfelder, K. (2020) Testis development and spermatogenesis in drones of the honey bee Apis mellifera L. Apidologie. 51, 935-955

Loher, W. (1961) The chemical acceleration of the maturation process and its hormonal control in the male of the desert locust. Proc. R. Soc. Lond. B 153, 380-397

Macrae, T.H. (2005) Diapause: diverse states of developmental and metabolic arrest. J. Biol. Res. 3, 3-14

Malka, O., Katzav-Gozansky, T., Hefetz, A. (2009) Uncoupling fertility from fertility-associated pheromones in worker honeybees (Apis mellifera). J. Insect. Physiol. 55, 205-209

Maurizio, A. (1954) Pollenernährung und Lebesvorgänge bei der Honigbiene (Apis mellifica L). Landwirtsch. Jahrb. Schweiz. 68, 115-182

O’Donnel, S., Jeanne, R.L. (1993) Methoprene accelerates age polyethism in workers of a social wasp (Polybia occidentalis). Physiol. Entomol. 18, 189-194 
Piulachs, M.D., Maestro, J.L., Bellés, X. (1992) Juvenile hormone production and accessory reproductive gland development during sexual maturation of male Blattella germanica (L.) (Dictyoptera, Blattellidae). Comp. Biochem. Physiol. A. 102, 477-480

Rader, R., Bradley, G. Howlett, B.G., Cunningham, S.A., Westcott, D.A., Edwards, W. (2012) Spatial and temporal variation in pollinator effectiveness: do unmanaged insects provide consistent pollination services to mass flowering crops? J. Appl. Ecol. 49, 126-134

Robinson, G.E., Strambi, C., Strambi, A., Feldlaufer, M.F. (1992) Reproduction in worker honey bees is associated with low juvenile hormone titers and rates of biosynthesis. Gen. Comp. Endocrinol. 87, 471-480

Shpigler, H.Y., Herb, B., Drnevich, J., Band, M., Robinson, G.E., Bloch, G. (2020) Juvenile hormone regulates brain-reproduction tradeoff in bumble bees but not in honey bees. Horm. Behav. 126, 104844

Sgolastra, F., Bosch, J., Molowny-Horas, R., Maini, S., Kemp, W.P. (2010) Effect of temperature regime on diapause intensity in and adult - wintering Hymenopteran with obligate diapause. J. Insect. Physiol. 56, 185-194

Sgolastra, F., Kemp, W.P., Buckner, J.S., Pitts-Singer, T.L., Maini, S., Bosch, J. (2011) The long summer: Pre-wintering temperatures affect metabolic expenditure and winter survival in a solitary bee. J. Insect. Physiol. 57, 1651-1659

Simonet, G., Poels, J., Claeys, I., Van Loy, T., Franssens, V., De Loof, A., Vanden Broeck, J., (2004) Neuroendocrinological and molecular aspects of insect reproduction. J. Neuroendocrinol. 16, 649-659

Tatar M., Yin, C.M. (2001) Slow aging during insect reproductive diapause: why butterflies, grasshoppers and flies are like worms. Exp. Gerontol. 36, 723-738

Treanore, E., Amsalem, E. (2020) The effect of intrinsic physiological traits on diapause survival and their underlying mechanisms in an annual bee species Bombus impatiens. Conserv. Physiol. 8, coaa103

Wasielewski, O., Wojciechowicz, T., Giejdasz, K., Krishnan, N. (2011) Influence of methoprene and temperature on diapause termination in adult females of the over-wintering solitary bee, Osmia rufa L. J. Insect. Physiol. 57, 1682-1688

Wigglesworth, V.B. (1936) The function of the corpus allatum in the growth and reproduction of Rhodnius prolixus (Hemiptera). Quart. J. Microscop. Sci. 79, 91-21

Wilkaniec, Z., Giejdasz, K. (2003) Suitability of nesting substrates for cavity-nesting bee Osmia rufa. J. Apic. Res. 42, 29-31

Woyke, J., Jasinski, Z. (1973) Influence of external conditions on the number of spermatozoa entering the spermatheca of instrumentally inseminated honeybee queens. J. Apic. Res. 12, 145-149

Wójtowski, F., Wilkaniec, Z. (1978) Rearing and utilization of solitary bees settled in nest traps (in Polish). Instrukcje Wdrożeniowe AR Poznań 1-10

Yamamura, S., Ikarashi, M., Sasaki, M. (2008) Dual photoperiodic regulation to enable univoltine life cycle In Alpine silver-Y moth, Syngrapha ottolenguii (Noctuidae: Plusiinae) without obligatory diapause. Appl. Entomol. Zool. 43, 105-112

Zdarek, J., Ctvrtecka, R., Hovorka, O., Kostal, V. (2000) Activation of gonads and disruption of imaginal diapause In the apple blossom weevil, Anthonomus pomorum (Coleoptera: Curculionidae), with juvenoids in laboratory and field trials. Eur. J. Entomol. 97, 25-31

Publisher's Note Springer Nature remains neutral with regard to jurisdictional claims in published maps and institutional affiliations. 